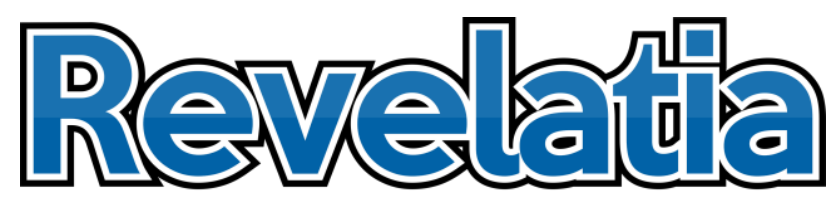

Jurnal Ilmu Al-Qur'an and Tafsir

P-ISSN: 2721-5962 I E-ISSN: 2721-768X

\title{
Aplikasi Pendekatan Hermeneutika Al-Qur'an Nasr Hamid Abu Zayd terhadap QS. Al-Nisa' (4): 3 dan Al-Nahl (16): 3-4
}

\author{
Wely Dozan \\ Magister Studi Qur'an Hadis \\ Universitas Islam Negeri Sunan Kalijaga Yogyakarta \\ Email: welydozan77@gmail.com \\ Qohar Al Basir \\ Magister Studi Qur'an Hadis \\ Universitas Islam Negeri Sunan Kalijaga Yogyakarta \\ Email: qoharalbasyir90@gmail.com
}

\begin{abstract}
Abstrack:
Nasr Hamid Abu Zayd is a Muslim intellectual whose ideas on the Qur'an was contradicting many Egyptian Muslims. He mentioned the Qur'an as a cultural product in the development of Arabic culture because it was revealed gradually according to the situation at that time. Through five contexts, he offered interpretation of the Qur'an that does not distort the text and are based on socio-cultural (hermeneutic). This paper focuses on studying the hermeneutic approach of Abu Zayd and its implications on the interpretation of QS. 4: 3 and 40: 57. The research method is library research by browsing data from books, books, journals and other kinds of literature related to the problem. The results of the study show that hermeneutics can be an alternative methodology for bridging dialogue between text and reality in producing contextual understanding without leaving the Qur'anic chronology and history while obtaining critical understanding. Instead of permitting polygamy, QS. 4: 3, according to him, actually accentuates the context of monogamy. This is in accordance with the context to protect society. Meanwhile, the interpretation QS. 40: 57 that the creation of heavens and earth through al-haq indicates the meaning (materials of creation) instead of creation activity (process).
\end{abstract}

\section{Abstrak:}

Nashr Hamid Abu Zayd adalah intelektual Muslim yang banyak mendapat penolakan dari para ulama Mesir terkait pemikirannya tentang al-Qur'an. Ia mengatakan bahwa alQur'an adalah produk budaya yang hidup dan tumbuh seiring perkembangan budaya Arab karena diturunkan secara berangsur sesuai kondisi pada masa itu. Melalui lima konsep kuncinya, Abu Zayd menawarkan penafsiran al-Qur'an tanpa meninggalkan historitas teks dari segi sosio-kultural (secara hermeneutika) agar Al-Qur'an tidak diartikan secara struktual dan tendensius. Tulisan ini fokus mengkaji hermeneutika Abu Zayd dan implikasinya dalam penafsiran Q.S. 4: 3 dan 40: 57. Metode penelitian ini 
adalah library research melalui pengumpulan data dari buku, kitab, jurnal, dan literatur terkait. Hasil penelitian menujukkan bahwa hermeneutika dapat menjadi metodologi alternatif untuk mendialogkan teks dan realitas dalam rangka menghasilkan pemahaman yang kontekstual tanpa meninggalkan kronologi dan kesejarahan al-Qur'an demi mendaptkan pemahan kritis. Adapun implikasi dalam penafsiran QS. 4: 3 adalah bahwa menurut Abu Zayd, teks tersebut tidak berbicara soal kebolehan poligami, melainkan justru konsep monogami dalam pernikahan sesuai dengan konteks dan perkembangan yang dihadapi masyarakat. Sedangkan penafsiran QS. 40: 57 bahwa penciptaan langit dan bumi melalui al-haq adalah makna (bahan penciptaan) bukan sebuah aktivitas penciptaan (proses).

Kata kunci: Pendekatan; Hermeneutika; Al-Qur'an; Nasr Hamid Abu Zayd 


\section{PENDAHULUAN}

Perkembangan wacana pemikiran Islam dewasa ini banyak sekali memunculkan pandangan-pandangan baru terkait al-Qur'an, utamanya dari para modernis. Sebut saja Muhammad Arkoun yang menyatakan bahwa al-Qur'an yang ada pada kita saat ini adalah edisi dunia sebab al-Qur'an yang sebenarnya adalah yang diamankan dalam lauh mahfuz (preserved tablet) dan tetap berada bersama-Nya. Karena itu, menurutnya, kita tidak perlu menyakralkan al-Qur'an edisi dunia yang telah mengalami modifikasi, revisi, dan substitusi. ${ }^{1}$ Begitu juga halnya hal dengan Nashr Hamid Abu Zayd yang menyatakan bahwa al-Qur'an adalah produk budaya (muntaj tsaqafi) yang tidak bisa terpisahkan dari struktur budaya Arab. ${ }^{2}$

Pernyataan Abu Zayd tersebut tentu tidak lepas dari latar belakangnya sebagai sastrawan. Dimungkinkan, teori-teori sastra yang ia pelajari berpengaruh terhadap pemikiran-pemikirannya. Jika ditelusuri, anggapan bahwa teks al-Qur'an adalah produk budaya terimbas banyak dari teori kritik sastra. Lucian Goldman, misalnya, menganggap bahwa karya sastra adalah sebuah struktur sebagai produk sejarah yang terus berlangsung. Sementara itu, sosiologi sastra memandang karya sastra dihasilkan melalui hubungan bermakna antara subyek kreator dan masyarakat.

Teori ini memandang karya sastra sebagai bagian dari masyarakat, yakni sebagai dokumen sosial. Seorang pengarang tidak mungkin menciptakan suatu karya tanpa realitas yang melatarbelakanginya. Oleh karena itu, karya sastra adalah produk masyarakat tertentu. Bisa jadi, inilah teori sastra yang mempengaruhi Abu Zayd di balik kesimpulannya bahwa al-Qur'an adalah produk budaya. ${ }^{3}$ Dari situlah, menurutnya, teks merupakan hal yang harus terus digali esuai tuntutan reformasi dan arah perubahan zaman. Hal ini sebagaimana dikutip Moch. Nur Ichwan bahwa dalam buku Mafhum alNass (konsep teks), Abu Zayd tidak memberikan pengertian yang pasti dan jelas dari pendapatnya perihal pengertian "teks." Ia hanya mengutip pengertian tentang teks berdasarkan pengertian modern sebagai berikut:

“Teks dalam definisi kontemporer: Serangkaian tanda yang tertata dalam suatu susunan dari hubungan-hubungan yang memproduksi makna keseluruhan dan membawa suatu pesan. Pesan tersebut bisa berupa tanda-tanda dengan bahasa asli-lafal-lafal-ataupun dengan tanda-tanda dalam bahasa lain. Sesungguhnya, keseragaman tanda dalam susunan pesan itulah yang membuat teks." 4

Selain itu untuk memberi pengertian eksplanatif tentang teks, Abu Zayd membedakan antara nas (teks) dan mushaf (buku). Menurutnya, nas (teks) berarti dalalah (makna) yang memerlukan pemahaman, penjelasan, dan interpretasi. Sementara itu,

${ }^{1}$ Hasan Hanafi, Hermeneutika Al-Qur'an, (Yogyakarta: Pesantren Nawesea Press, 2009), 35.

${ }^{2}$ Nasr Hamid Abu Zayd, Mafhum al-Nass, (Kairo: Al-Hai'ah al-Misriyyah al'Ammah li alKutub, 1990), 27.

${ }^{3}$ Nasr Hamid Abu Zayd, Mafhu>m al-Nass..., 13.

${ }^{4}$ Moch. Nur Ichwan, Meretas Kesarjanaan Kritis al-Qur'an: Teori Hermeneutika Nasr Hamid Abu Zayd, (Jakarta: Teraju, Cet.I, 2003), 65. 
mushaf (buku) tidaklah demikian karena ia telah tertransformasikan menjadi sesuatu (syai') baik berupa karya estetik ataupun alat untuk mendapatkan berkah Tuhan. Masih menurut Abu Zayd, teks terbagi menjadi dua, yakni teks primer (al-nass al-asliy) dan teks sekunder (al-nass al-tsanawiy). Teks primer adalah al-Qur'an dan teks sekunder adalah sunnah Nabi yang berperan sebagai komentar tentang teks primer. Adapun teks-teks keagamaan yang dihasilkan dari ijtihad-ijtihad para ulama, ahli fiqh, mufasir dianggap sebagai teks sekunder selanjutnya. ${ }^{5}$

Berangkat dari sini, penulis mempunyai kegelisahan untuk membaca pemikiran Abu Zayd khususnya dalam hermeneutika al-Qur'an yang membuatnya cukup kontroversial hinga mendapat kecaman dari ulama Mesir. Di sisi lain, dalam ranah qur'anic studies yang relatif baru dalam studi Islam kontemporer, pemikirannya sudah cukup populer dan bahkan sudah banyak diteliti kalangan akademisi. Namun demikian, hal yang lebih penting adalah sisi kontroversial seorang Abu Zayd yang juga mempunyai perbedaan cukup signifikan dibandingkan tokoh hermeneut Muslim lainnya.

Harapan penulis, penelitian ini dapat memberi kontribusi pemikiran terhadap model pembacaan al-Qur'an dengan mengusung hermeneutika sebagai cara untuk memahami (verstehen $)^{6}$ dan melahirkan pemahaman yang progresif dan kontekstual dalam pengembangan keilmuan Studi ke-Islaman dan hukum Islam ke depan. ${ }^{7}$ Oleh karena itu, studi Islam ke depan memerlukan langkah-langkah penting untuk menafsirkan teks-teks keagamaan baik dalam ranah qur'anic studies maupun sunnah agar lebih bersifat humanis, transformatif, kontekstual, dialogis, negosiatif, humanistik, dan dekonstruktif. ${ }^{8}$ Ini dilakukan melalui proses pengkajian terhadap hermeneutika al-Qur'an ala Abu Zayd pada penafsiran Q.S. An-Nisa' (4): 3 dan Q.S. al-Mu'minun (40): 57 yang diklaim merekonstruksi metodologi kontekstual.

\section{METODE PENELITIAN}

Menurut lokasi pengambilan datanya, penelitian dapat dibagi menjadi tiga, yaitu field research, library research dan laboratorium. Penelitian ini adalah penelitian pustaka atau library research dengan data dari buku, kitab, serta literatur terkait. ${ }^{9}$ Adapun pendekatan yang digunakan adalah historis-analitis, yaitu dengan merunut akar-akar historis secara

${ }^{5}$ Nashr Hamid Abu Zayd, Al-Imam al-Syafi wa Ta'sisu al-Idiyulujiyyah al-Wasatiyyah, (Beirut: Al-Markaz al-Tsaqafi al-'Arabi, 2007), 22.

${ }^{6}$ Kaelan, Metode Penelitian Agama Kualitatif Interdisipliner, (Yogyakarta: Paradigma, 2010),. 165.

${ }^{7}$ Amin Abdullah, "Pendekatan Hermeneutik dalam Studi Fatwa-fatwa Keagamaan: Proses Negosiasi Komunitas Pencari Makna Teks, Pengarang, dan Pembaca", dalam Pengantar buku Khaled M. Abou El-Fadl, Atas Nama Tuhan dari Fikih Otoriter ke Fikih Otoritatif, (Jakarta: Serambi, 2004), xvii.

${ }^{8}$ Nasr Hamd Abu Zayd, Rethinking Qur'an: Towords a Humanistic Hermeneutics, (Amsterdam: Humanistics University Press, 2004), 22-37. Ghanim, Kritik Ortodoksi..., viii. Bandingkan dengan Fazlur Rahman, Membuka Pintu Ijtihad, (Bandung: Pustaka, cet. III, 1995), 149.

${ }_{9}^{9}$ Usman, Ilmu Tafsir, (Yogyakarta: Teras, 2009), 319 
analitis untuk melihat aplikasi hermeneutika Abu Zayd dalam penafsiran Q.S. An-Nisa' [4]: 3 dan al-Mu'minun (40): 57. Dengan pendekatan historis ini, penulis menunjukkan bagaimana pergeseran konsep change and continuity dalam penafsiran Abu Zayd. ${ }^{10}$

\section{SEKILAS BIOGRAFI DAN KARIER INTELEKTUAL NASR HAMID ABU ZAYD}

Nasr Hamid Abu Zayd yang bernama lengkap Nasr Hamid Rizk Zayd, lahir di Tanta, ibu kota provinsi al-Gharbiyah, Mesir, pada 10 Juli 1943. Ia dilahirkan dan dibesarkan di tengah keluarga yang taat beragama, relijiyus, dan tekun beribadah. Pengajaran agama pertamanya ia terima sejak dini di keluarga. ${ }^{11}$ Bapaknya adalah aktivis Al-Ikhwan Al-Muslimin pengikut Sayid Qutb yang pernah dipenjara menyusul eksekusi Sayid Qutb. Ia mulai belajar dan menulis serta menghafal Al-Quran pada usia delapan tahun sehingga ia dipanggil "Syaikh Nasr" oleh anak-anak di desanya.

Ketika pada 1954 Al-Ikhwan Al-Muslimun menjadi gerakan yang kuat dan menyebar di seluruh desa, ia ikut bergabung dalam organisasi ini. Ketika itu usianya masih 11 tahun. Selanjutnya, Abu Zayd menempuh pendidikan tingginya dari S1 sampai S3 di jurusan Sastra Arab Universitas Kairo. Ia adalah sosok intelektual dengan berbagai prestasi mengagumkan sehingga kerap mendapat penghargaan dari kampusnya.

Tak sampai di situ, ia bahkan dipercaya sebagai dosen pengampu mata kuliah studi Al-Qur'an dan hadist di almamaternya tersebut sejak 1972. Inilah yang mengubah fokus kajiannya dari bidang linguistik dan kritik sastra, meskipun sejak 1985 hingga 1989, ia pernah menjadi dosen tamu Bahasa Arab di Universitas Osaka, Jepang. Ia kemudian banyak mengkaji Al-Qur'an menggunakan pendekatan sastra, linguistik, hermeneutika, dan sosial-humaniora. Sejak 1978 hingga 1980, ia tinggal di Amerika karena memperoleh beasiswa untuk penelitian doktoralnya di Institute of Middle Eastern Studies, University of Pennsylvania. Belakangan, penelitian itulah yang melambungkan namanya sekaligus melekatkan sosoknya dengan kontroversi.

Ia divonis murtad dalam peristiwa yang kerap disebut Qadiyyah Nasr Hamid Abu Zayd. Peristiwa ini tak pelak begitu meramaikan diskursus keagamaan. Tak hanya itu, pemurtadan terhadapnya masih berlanjut hingga pengadilan banding Kairo mengharuskan Abu Zayd menceraikan istrinya, Dr. Ibtihal Yunes, dengan alasan bahwa seseorang yang murtad tidak boleh menikahi wanita muslimah. Semenjak peristiwa itu, Abu Zayd beserta istrinya meninggalkan Mesir dan menetap di Belanda. Di situ ia menjadi profesor tamu studi Islam pada Universitas Leiden sejak 26 Juli 1995. hingga pada 27 Desember 2000, ia dikukuhkan sebagai Guru Besar tetap di Universitas tersebut. ${ }^{12}$

Adapun karya-karya Abu Zayd di antaranya adalah sebagai berikut: 1982) AlIttijâh al-Aqli fi al-Tafsirr: Dirâsat fi Qadiyyaț al-Majâz inda al-Mutazilat (Kecenderungan Rasional dalam Penafsiran: Studi atas Persoalan Metafor dalam AlQuran menurut kalangan

${ }^{10}$ Abdul Mustaqim, Metode Penelitian Al-Qur'an dan Tafsir,,, 53.

${ }^{11}$ Moch. Nur Ichwan, "Nasr Hamid Abu Zayd Dan Studi Al-Quran", Risalah, N0. 11 Th. XXXV, Januari 1998, 60 .

${ }^{12}$ Ibid.,198 
Mutazilah), Beirut. (1983) Falsafaț al-Tawil: Dirâsat fi Tawil alQurân inda Mubyi al-Dîn Ibn Arabî (Filsafat Hermeneutik: Studi atas Hermeneutik AlQuran Muhyi al-Din Ibnu Arabi), Kairo.(1990) Mafhūm al-Nashsh: Dirâsat fi Ulum al-Quran (Konsep Teks: Studi Ilmu-Ilmu AlQuran), Kairo. (1994) Naqd al-Khitâb al-Dînî (Kritik Wacana Keagamaan), Kairo: Sina li alNasyr, 1994 (edisi ke-2), diterjemahkan dalam Bahasa Jerman oleh Cherifa MagdiIslam dan Politic : Kritik des religiosen Diskursus. Frankfrut : Dipa, 1996. (1995) Al-Takfir fi Zaman al-Tafkir: Didda aljahl wa al-Zayf wa al-Khurafaț (Pemikiran di Zaman Pengkafiran: Menentang Kebodohan, Kekeliruan dan Khurafat), Kairo. (1995) al-Nash, al-Sulthat, al-Haqiqat: alFikr al-Dîn bayna Irâdat al-Marifat (Teks, Kekuasaan, dan Esensi: Pemikiran Keagamaa $n$ antara Kehendak Pengetahuan), Kairo. (1999) Dawâir al-Kawf: Qiraat fi Khitâb alMarat (Wilayah Ketakutan: Pembacaan atas Wacana Perempuan), Dar al-Beida. Al-Imâm al-Syâfii wa Tasîs al-Aidiulujiyyah al-Washatiyyah. Kairo : Sina li al-Nasyr. ${ }^{13}$

\section{TEORI DAN PENDEKATAN YANG DITAWARKAN NASR HAMID ABU ZAYD}

Ada dua asumsi dasar yang dibangun Abu Zayd untuk menjelaskan pandanganpandangannya terkait status al-Qur'an sebagai sebuah teks: Pertama, ia menyatakan bahwa teks-teks keagamaan berasal dari bahasa yang bentuknya sama dengan teks-teks lain dalam kajian budaya. Kedua, berangkat dari asumsi pertama, ia menyatakan bahwa umat Islam saat ini memerlukan kebebasan mutlak dari otoritas teks-teks keagamaan (khususnya al-Qur 'an) demi melahirkan pemahaman keagamaan yang sesuai dengan konteks saat ini. Dalam satu ungkapan, ia menjelaskan seperti berikut:

“Telah tiba saat mengevaluasi dan melangkah ke era pembebasan tidak hanya dari kekuasaan teks-teks agama saja, tetapi juga dari setiap kekuasaan yang mengekang ruang gerak manusia di dunia ini. Kita harus segera bertindak sebelum disapu oleh banjir bandang" 14

Pandangan Abu Zayd ini tidak bisa dilepaskan dari konsep wahyu yang demikian menyokong asumsi-asumsinya soal teks. Menurutnya, proses turunnya al-Qur'an kepada Nabi Muhammad SAW terjadi melalui dua tahapan. Pertama adalah tahap tanzil, yaitu proses turunnya al-Qur'an secara vertikal dari Allah kepada Jibril. Kedua adalah tahap ta'wil, yaitu proses di mana Nabi Muhammad SAW menyampaikan al-Qur'an dengan bahasanya, yaitu Bahasa Arab, yang sesuai dengan pemahaman masyarakat Arab ketika itu sebagai penerima Al-Qur'an pertama. ${ }^{15}$ Proses ini dapat diilustrasikan dengan gambar berikut:



${ }^{13}$ Nasr Hamid Abu Zayd, Al-Quran; Hermeneutik dan Kekuasaan, terj. Mochammad Nur Ichwan (Bandung: RQiS,2003), 207.

${ }^{14} \mathrm{Nashr}$ Hamid Abu Zayd, Al-Imam al-Syafi'i... 36.

${ }^{15}$ Nasr Hamid Abu Zayd, Naqd al-Khitab al-Diny... 127. 106

REVELATIA: Jurnal Ilmu Al-Qur'an dan Tafsir

Vol. 1, No. 2, November 2020 
Keterangan: Proses Allah Swt menurunkan Al-Qur'an pada Nabi Muammad SAW disebut tanzil, sedangkan proses penyampaian dari Nabi Muhammad ke umat Islam dinamakan $t a^{\prime}$ wil.

Ilustrasi di atas menjelaskan bahwa konsep wahyu menurut Abu Zain telah berubah dari tanzil menjadi ta'wil. Artinya, al-Qur'an yang ada sekarang hanya merupakan bentuk pemahaman Nabi Muhammad SAW sebagai penerima wahyu. Untuk mengintegrasikan metode kritik sastra dan hermeneutika yang diterapkan, Abu Zain menempatkan Nabi Muhammad SAW sebagai 'pengarang' al-Qur'an sebab interaksinya dengan budaya di mana wahyu diturunkan dan bentuk wahyu dalam Bahasa Arab. Menurut Abu Zain, bahasa Tuhan berbeda dengan bahasa manusia.

Pandangan ini merupakan keberanian intelektual yang menerobos ikatan-ikatan sakralitas keagamaan baku serta mapan sekaligus menyelisihi keyakinan kaum Muslimin. Apalagi, Abu Zain mengatakan bahwa fenomena wahyu yang diterima Nabi Muhammad SAW tak lain adalah imajinasi beliau sebab ia menerimanya dalam kondisi kemiskinan, yatim piatu, serta akrab dengan penganiayaan. ${ }^{16}$

Lepas dari itu, dalam kerangka yang lebih luas, hermeneutika dalam konteks keIslam-an merupakan sekumpulan metode dan teori yang difokuskan pada upaya memahami teks, baik itu Al-Qur'an maupun Sunnah Nabi. ${ }^{17}$ Terdapat sedikitnya tiga tren utama dalam pembacaan al-Qur'an kontemporer.

Pertama adalah teori yang berpusat pada pengarang (author). Asumsi dasar yang dibangun adalah bahwa makna teks merupakan makna yang dimaksudkan pengarang. Dalam konteks Al-Qur'an, dengan demikian, yang paling banyak mengetahui maksud pengarang adalah Nabi Muhammad SAW, sahabat, tabi'in, dan para ulama berikutnya. Tanpa bantuan otoritas keagamaan tersebut. pembaca akan sulit mengetahui maksud author (syari') secara obyektif. Sedangkan dalam konteks hadis yang merupakan teks sekunder, otoritas pemaknaan ada pada sahabat, tabi'in, dan ulama.

Kedua adalah teori yang berpusat pada teks. Asumsi dasarnya adalah bahwa makna suatu teks berada pada teks itu sendiri. Dengan kata lain, penulis tidak begitu berarti sehingga teks bersifat independen, otoritatif, dan juga obyektif.

Ketiga adalah teori yang berpusat pada penafsir atau pembaca (reader). Asumsi dasarnya adalah bahwa teks tergantung pada apa yang diterima dan diproduksi oleh penafsir, sehingga teks bisa ditafsirkan ke arah yang difungsikan oleh pembaca. ${ }^{18}$

Dalam konteks ini, metode hermeneutika Abu Zayd juga berangkat dari gagasannya terhadap teks, khususnya Al-Qur'an. Ia menyebutkan perlunya penekanan

${ }^{16}$ Moch. Nur Ichwan, Studi al-Qur'an Kontemporer: al-Qur'an sebagai Teks,(Yogyakarta: PT. Tiara Wacana Yogya, 2002), 165.

${ }^{17}$ Moch. Nur Icwan, ibid., 59. Baca juga, Moch. Nur Ichwan, dalam Abdul Mustaqim dan Sahiron Syamsuddin (ed.), Studi Al-Qur'an Kontemporer, 149; Fahruddin Faiz, Hermeneutika AlQur'an, 99; Adian Husaini dan Henri Salahuddin, "Studi Komparatif ...", 33-42.

${ }^{18}$ Moch. Nur Ichwan, “Teori Teks dalam Hermeneutika ...", 27-40. 
historisitas teks Al-Qur'an, kesadaran sejarah atasnya, serta sikap kritis terhadap teks dan konteks sejarahnya. Hubungan antara pembaca dan teks secara dialektis (jadaliyyah) ia pandang sangat penting di kalangan para penafsir agar mereka tidak terjebak dalam ideologisasi penafsiran. ${ }^{19}$

Dari situ, Abu Zayd melahirkan metode interpretasi yang bercorak humanis dan dialogis kemudian menamainya dengan "hermeneutika humanistik". Ia menyamakan hermeneutikanya dengan konsep $t a^{\prime}$ wil dalam Islam, bukan talwin atau ideologisasi. Akan tetapi, ia juga dengan tegas membedakan tafsir dan ta'wil. Tafsir menurutnya befungsi menyingkap makna suatu teks, sedang $t a^{\prime}$ wil bertugas agar makna teks tersebut memiliki keterkaitan fungsional dengan kondisi saat ini. Ta'wil, dengan demikian, memiliki pengertian yang sama dengan hermeneutika dalam hal pemaknaannya.

Lebih lanjut, ia melihat al-Qur'an sebagai sebuah "teks" dan bahwa peradaban Arab Islam merupakan sebuah "peradaban teks". Artinya, dasar-dasar ilmu dan budaya Arab-Islam telah tumbuh dan berdiri tegak di atas suatu landasan di mana "teks" menjadi pusatnya. ${ }^{20}$ Meski demikian, bukan berarti "teks"lah yang membangun peradaban dengan sendirinya. Interaksi dialektis antara manusia. "teks" dan segala realitaslah yang berperan penting dalam membentuk ekonomi, sosial, budaya, politik dan seluruh aspek kehidupan..$^{21}$

Kemudian untuk memaparkan pengertian yang bisa menjelaskan arti sebuah teks, Abu Zayd membedakan antara nash (teks) dan mushaf (buku). Menurutnya, nash (teks) berarti dalalah (makna) yang memerlukan pemahaman, penjelasan, dan interpretasi. Ia juga memetakan teks menjadi dua kategori, yakni teks primer (al-nass al-asliy) dan teks sekunder (al-nass al-tsanawiy). Teks primer adalah al-Qur'an dan teks sekunder adalah sunnah Nabi yang berperan sebagai komentar atau penjelas dari teks primer. Sementara itu, teks-teks keagamaan yang dihasilkan dari ijtihad-ijtihad para ulama, ahli fiqh, mufasir dianggap sebagai teks sekunder. ${ }^{22}$ Adapun mushaf (buku) tidaklah demikian sebab ia telah tertransformasi menjadi sesuatu (syai'), baik berupa karya estetik ataupun alat untuk mendapatkan berkah Tuhan. ${ }^{23}$

Kaitannya dengan teks, Abu Zayd meyakini bahwa dengan menyelami arti realitas di sekitar teks, teks al-Qur'an adalah merupakan produk budaya (muntaj tsaqafi) karena terbentuk atas realitas sosial budaya selama dua puluh tahun-an. Proses kemunculan dan interaksinya dengan realitas budaya dalam kurun waktu tersebut merupakan fase "keterbentukan" (marhalah al-takawwun wa al-tasyakkul). Fase selanjutnya adalah fase "pembentukan" (marhalah al-takwin wa al-tasykul), di mana al-Qur'an

\footnotetext{
19Suharmadi Assumi, "Nasr Hamid Abu Zayd dan Metode Hermeneutika", http://islamlib.com/en/page.php?page=comment\&mode=view\&art_id=6

${ }^{20}$ Nasr Hamid Abu Zayd, Mafhum al-Nass, (Kairo: Al-Hai'ah al-Mis\}riyyah al'Ammah li alKutub, 1990), 27.

${ }^{21} \mathrm{Ibid}, 11$

${ }^{22} \mathrm{Nash}$ Hamid Abu Zayd, Al-Imam al-Sya fi wa Ta'si su al-Idiyulujiyyah alWasatiyyah, (Beirut: Al-Markaz al-Tsaqafi al-'Arabi, 2007), 22.

${ }^{23}$ Nasr Hamid Abu Zayd, Mafhum al-Nass, 15. 
kemudian membentuk budaya baru sehingga dengan sendirinya ia juga menjadi "produsen budaya" (muntaj tsaqafi).

Selain sebagai produk kemudian produsen budaya, Abu Zayd juga menekankan bahwa al-Qur'an merupakan pesan dengan teks linguistik yang berkarakter. Salah satunya adalah dua dimensi yang terlihat kontradiktif, yakni antara konsep tafsir dan ta'wil dalam pengertian berbeda dari yang tersebut di atas. Dalam konteks ini, tafsir berarti menyingkap sesuatu yang tersembunyi agar bisa diketahui dengan media tafsirah. Sementara itu, $t a^{\prime}$ wil berarti kembali ke asal-usul sesuatu untuk mengungkapkan ma'na dan magza. Ma'na adalah dalalah atau arti yang dibangun berdasarkan gramatikal teks, sedangkan magza menunjukkan makna dalam konteks sosio-historis. ${ }^{24}$

Hubungannya dengan konteks, al-Qur'an menurut Abu Zayd memiliki beberapa level konteks, yakni konteks sosio-kultural (al siyaq al saqafi al-ijmali), konteks eksternal (alsiyaq al-khariji), konteks internal (al-siyaq al-dakhili), konteks bahasa (al siyaq al-lugawi) dan konteks pembacaan atau pentakwilan (siyaq qiraah atau siyaq ta'wili). Ia mensyaratkan pengalihan makna melalui terpenuhinya kelima konteks tersebut. Ini tidak berbeda dengan perubahan dalam kajian semiotika yang memandang bahwa fakta-fakta dan fenomena-fenomena masyarakat serta kebudayaan merupakan tanda-tanda yang bermakna, sementara bahasa merupakan bagian dari fakta tersebut. ${ }^{25}$

Tujuan utama mengkaji Al-Qur'an sebagai sebuah teks, menurutnya, adalah mengkorelasikan kembali studi Al-Qur'an dengan studi kritik sastra (ad-dirasat aladabiyyah wa an-naqdiyyah). Karena al-Qur' an adalah teks, maka ia melihat bahwa studi alQur'an juga perlu mengkaji dimensi linguistik sekaligus sastrawi di dalamnya. Untuk itu, ia mengadopsi teori-teori mutakhir dalam teori interpretasinya, seperti lingustik, semiotik, dan hermeneutika. Dengan merumuskan pemahaman keagamaan dan melakukan interpretasi secara obyektif menggunakan pendekatan ini, Abu Zayd melihat bahwa racikan tersebut akan mampu menghindarkan penafsir/pembaca dari kepentingan-kepentingan ideologis maupun pembacaan tendensius (al-qira'ah almughridah). Dua kecenderungan tersebut, menurut Abu Zayd, bisa diantisipasi dengan tawarannya yang ia sebuat pembacaan produktif (al-qira'ah al-muntijah) dan kontekstual (alqira'ah al-siyaqiyyah). ${ }^{26}$

\section{APLIKASI PENDEKATAN HERMENEUTIKA NASR HAMID ABU ZAYD}

Di antara beberapa teori hermeneutika yang ditawarkan Abu Zayd dalam menafsirkan teks al-Qur'an, secara spesifik penulis akan mengaplikasikannya dalam dua ayat berikut:

\footnotetext{
${ }^{24}$ Kurdi. dkk. Hermeneutika al-Qur'an dan Hadis, (Yogyakarta: Elsaq Press, 2010), 124-125.

${ }^{25} \mathrm{Ibid}, 130$

${ }^{26}$ Muhammad Chirzin, Fenomena Al-Qur'an "Diskusi Pemikiran Ulil Absar-Abdalla, Lutfhi Assyaukhani, dan Abd Moqsith Ghazali tentang Metodologi Studi Al-Qur'an, (Yogyakarta: Pustaka Pelajar, 2018), 225.
} 
Aplikasi Penafsitan Q.S. an-Nisa' (4): 3

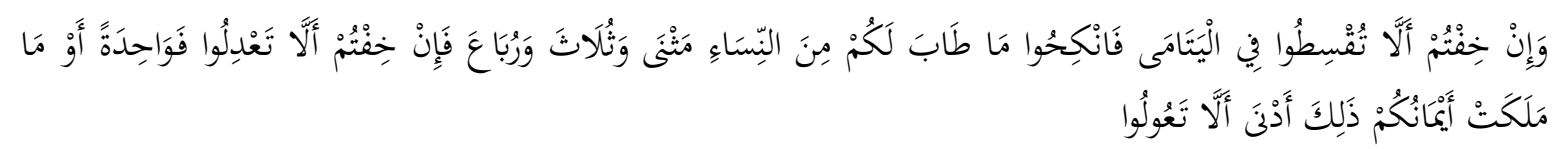

Artinya: Dan jika kamu takut tidak akan dapat Berlaku adil terhadap (hakhak) perempuan yang yatim (bilamana kamu mengawininya), Maka kawinilah wanita-wanita (lain) yang kamu senangi : dua, tiga atau empat. kemudian jika kamu takut tidak akan dapat Berlaku adil Maka (kawinilah) seorang saja atau budak-budak yang kamu miliki. yang demikian itu adalah lebih dekat kepada tidak berbuat aniaya. ${ }^{27}$

Poligami dalam Kamus Besar Bahasa Indonesia berarti tindakan seorang laki-laki yang menikah dengan perempuan lebih dari satu dalam waktu yang sama. Sebagai sistem perkawinan khusus, poligami juga dikenal dengan istilah "poligini". Perilaku ini telah ada sejak berabad-abad yang lalu. Kisah-kisah kehidupan nabi dalam Taurat pun turut menggambarkan poligami sebagai kebiasaan yang diterima masyarakat pada saat itu. Menurut Hasan Halthout ${ }^{28}$, Nabi Sulaiman a.s. mempunyai 700 orang istri dari kalangan merdeka dan 300 orang istri dari kalangan budak. Para pemikir Islam umumnya berbeda pandangan perihal kebolehan berpoligami. Pertama adalah mereka yang berpendapat bahwa poligami tidak diperbolehkan kecuali dalam beberapa kondisi, sedang kedua adalah mereka yang menyakini kebolehannya. Golongan pertama umumnya terdiri dari para pemikir belakangan, sementara yang kedua adalah para ulama klasik dan sebagian kecil pemikir belakangan. ${ }^{29}$

Perbedaan ini kemudian menggiring pada diskusi perihal penerapan hukum syariah secara literal hingga perdebatan keras tentang makna kaidah-kaidah fiqh dan penerapanya. Mereka yang mendukung poligami meyakini bahwa model pernikahan semacam itu mempunyai sandaran teks dan karenanya tidak mungkin bertentangan dengan kaidah fighiah apapun. Ini misalnya dikemukakan oleh sebagian pengikut salafi di Saudi yang bahkan mengatakan poligami sebagai bagian dari sunnah yang wajib diikuti. Sebagian lain dengan berlebihan mengatakan bahwa poligami sebenarnya merupakan ujian untuk menilai keimanan dan kekokohan hati perempuan/istri melalui kadar penerimaanya terhadap poligami sang suami. Asumsi dasarnya adalah bahwa baik tidaknya seorang istri bergantung dari kerelaannya untuk berbagi dengan perempuan kedua, ketiga, atau keempat yang dinikahi suaminya. ${ }^{30}$

Abu Zayd melihat bahwa ayat yang seringkali dijadikan landasan poligami (QS. 4: 3) sebenarnya menekankan ketidakbolehan menikahi wanita lebih dari satu. Ia

${ }^{27}$ Kementerian Agama RI, Al-Qur'an dan Terjemahan, (Bandung: Mikraj Khazanah Ilmu, 2016), 27.

28 Hathout, Hasan, Revolusi Seksual Perempuan, (Bandung: Mizan, 1995), 51.

${ }^{29}$ Khoiruddin Nasution, Riba dan Poligami studi atas Pemikiran Muhammad Abduh, Cet I, (Yogyakarta: Pustaka Pelajar dan ACAdeMIA), 1996, 108.

${ }^{30}$ Nasr Hamid Abu Zayd, Dawāir al-khauf: Qiraah fi Khitab al-Mara'h, (Bairut: Dar Al Baidha, Cet III, 2004), 268.

110

REVELATIA: Jurnal Ilmu Al-Qur'an dan Tafsir

Vol. 1, No. 2, November 2020 
menghubungkan ini dengan undang-undang terkait isu perempuan di Tunisia. Salah satu Undang-Undang Perkawinan yang masih menjadi perdebatan antara kalangan salafi dan liberal di negara tersebut, seperti ditulis Abu Zayd, adalah perihal poligami. Dari perdebatan tersebut, dengan gaya kritis ala akademisi, Abu Zayd memulai uraiannya dengan mengangkat kasus seorang wanita yang menolak permintaan suaminya untuk hamil sehingga ia dicerai di sebuah pengadilan dengan alasan pembatasan peran wanita di wilayah domestik keluarga dan rumah tangga. ${ }^{31}$ Pandangan Abu Zayd yang demikian sebenarnya tidak perlu diherankan mengingat dalam karyanya yang lain, ia kerap mendukung feminisme barat yang mendorong dan memperjungkan kemerdekaan wanita atas kesetaraan gender dengan asumsi dasar bahwa agama Islam diperuntukkan keselamatan dan kebaikan manusia tanpa perbedaan jenis kelamin. ${ }^{32}$

Menurut Abu Zayd, QS. An-Nisa [4]:3 harus dipahami dengan tiga [3] langkah pokok. ${ }^{33}$ Pertama adalah konteks ayat. Menurutnya, ayat tersebut mengkontraskan antara apa yang dimiliki tangan kanan (budak perempuan atau tawanan perang sebagai selir) dengan apa yang berada di tangan kiri (anak yatim perempuan) sehingga perintah untuk menikahi dua, tiga, atau empat perempuan terkesan mengusung semangat mempertahankan poligami. Padahal, tulis Abu Zayd, ada yang hilang dari kesadaran akan historisitas teks-teks keagamaan di mana ia merupakan teks linguistik sedangkan bahasa sendiri adalah produk sosial-kultural.

Abu Zayd melihat bahwa tuntunan Islam agar seorang laki-laki beristeri yang ingin menikah lagi meminta izin isterinya haruslah diletakkan dalam konteks hubungan antar manusia (laki-laki dan perempuan) sebelum kedatangan Islam. Pada masa praIslam, jangankan meminta izin untuk menikah lagi, batasan jumlah isteri saja tidak ada sebagai akibat dari sangat dominannya hukum kesukuan. Karena itu, imbauan untuk meminta izin serta pembatasan jumlah isteri tersebut sebenarnya sangatlah revolusioner. Lebih jauh, menurutnya, Islam mengubah pola pikir dan perilaku tersebut dengan mengharuskan Muslimin laki-laki menikahi satu orang perempuan saja sebagai upaya membebaskan perempuan dari dominasi laki-laki. ${ }^{34}$

Kedua adalah meletakkan teks dalam konteks al-Qur'an secara keseluruhan. Abu Zayd ingin mengungkapkan sesuatu yang tak terkatakan atau implisit. Dalam konteks poligami, ia menggarisbawahi ayat al-Qur'an yang menyarankan lelaki untuk memiliki seorang istri saja jika ia dikhawatirkan tidak bisa berbuat adil. Ayat dimaksud adalah: "jika kamu takut tidak bisa berbuat adil (terhadap mereka), maka seseorang saja". Terlebih, ayat lain, yakni Q.S. an Nisa [4]: 129 berikut menyatakan bahwa siapapun tidak akan mampu berbuat adil dalam kehidupan poligami:

${ }^{31}$ Nashr Hamid Abu Zayd, Wada'ir Al Khaif: Qira'ah..., 183.

${ }^{32}$ Nashr Hamid Abu Zayd, Wada'ir Al Khaif: Qira'ah..., 287-288.

${ }^{33}$ Nashr Hamid Abu Zayd, Wada'ir Al Khaif: Qira'ah..., 287-288.

34 Ibid, 288. 


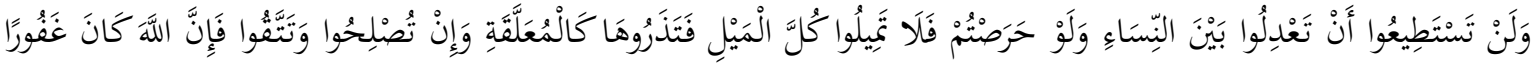

Artinya: "Dan kamu sekali-kali tidak akan dapat berlaku adil di antara isteri-istrimu, walaupun kamu sangat ingin berbuat demikian. Karena itu, janganlah Kamu terlalu cenderung (kepada yang kamu cintai), sehingga kamu biarkan yang lain terkatung-katung. Dan jika Kamu mengadakan perbaikan dan memelihara diri (dari kecurangan), maka sesungguhnya Allah Maha Pengampun lagi Maha Penyayang."

Ayat ini secara eksplisit memerintahkan lelaki yang berpoligami untuk bersikap adil di antara para istrinya meski bagian lain menegaskan bahwa hal demikian tidak mungkin dilakukan sebab sifat dasar manusia tidak memungkinkannya. Dari situ, Abu Zayd mengatakan bahwa poligami tidak bisa diterapkan pada zaman modern sekarang ini. ${ }^{35}$ Ia juga mengurai bahwa ayat tersebut menggunakan pengandai atau perumpamaan dengan huruf law yang yang berarti "jika". Menurutnya, ini menandakan negasi terhadap jawab al-syarth karena negasi yang sama juga terjadi pada kondisi syarth terkait. Hal lain yang menurutnya tidak boleh luput dari perhatian adalah pengunaan partikel lan (tidak akan pernah) yang berfungsi sebagai koroborasi ( $t a^{\prime} y i d$ ) di awal kalimat bahwa "kemampuan berlaku adil" adalah sebuah kemustahilan. ${ }^{36}$ Dari sini ia berkesimpulan perihal adanya negasi ganda, yakni negasi total terhadap kemungkinan bertindak adil dan terhadap kemungkinan memiliki keinginan kuat untuk berlaku adil. ${ }^{37}$

Kesimpulan tersebut senada dengan kerangka berpikir dasar Abu Zayd yang memetakan mabda' (prinsip), qaidah (kaidah) dan hukm (hukum). Kebebasan, hak hidup, dan kebahagiaan, baginya merupakan mabda'. Sementara itu, qaidah adalah derivasi dari mabda' sehingga 'ranting' tidak boleh menyalahi 'akar'. "Jangan mencuri, jangan berzina, jangan membuat kesaksian palsu, dan jangan menganggu orang lain" baginya merupakan qaidah yang muncul dari tiga point mabda' tadi. Dalam konteks jurisprudensi Islam, tujuan universal syariat (al-maqashid al-kulliyyah li al-syariah) adalah seperti yang digagas Al-Syathibi, yakni perlindungan terhadap agama, harta, akal, martabat, dan kehidupan. Abu Zayd melihat bahwa kelima prinsip ini berakar dalam teori hukum Islam (Ushul Al-Figh) dan tidak berkaitan dengan ilmu-ilmu Islam lain. Dari sini pula ia menawarkan tiga prinsip bersifat umum yang menurutnya universal. Pertama, rasionalisme (aqlaniyyah) sebagai antitesis dari jahiliyyah dalam pengertian mentalitas kesukuan dan tindakan emosional. Kedua, kebebasan (hurriyah) sebaga sebagai antitesis dari segala bentuk perbudakan ('ubudiyyah), dan ketiga, keadilan ('adalah) sebagai antitesis dari eksploitasi manusia (zhulm). ${ }^{38}$

Dalam konteks poligami, Abu Zayd memposisikan keadilan sebagai mabda' (prinsip), sementara batas maksimal jumlah istri (4 orang) adalah hukm. Hukm, tegasnya,

${ }_{35} \mathrm{Ibid}, 289$.

36 Mochammad Nur Ichwan, Meretas Kesarjanaan Kritis al-Quran: Teori Hermeneutika Nasr Hamd Abu Zayd, cet. Ke-1 (Jakarta: Teraju, 2003), 140.

${ }^{37}$ Ibid. 140.

38Ibi., 288-289. 
tidak bisa menjadi qaidah apalagi mabda'. Ia sekadar peristiwa spesifik dan relatif bergantung pada perubahan kondisi yang melingkupinya sehingga ketika terdapat kontradiksi antara mabda' dan hukm, hukm-lah yang harus 'dikalahkan' sementara mabda' tetap dipertahankan. Namun demikian, Zayd melihat bahwa Al-Qur'an sebenarnya tidak menetapkan hukum (tasyri') apapun terkait poligami selain hanya mengungkapkan limitasi atau batasan jumlah isteri. Ini, menurutAbu Zayd, adalah cara Al-Qur'an melarang poligami secara tidak langsung sebab limitasi tersebut mengindikasikan pelarangan (pengharaman) secara tersamar (al-tahrim al dhimni). ${ }^{39}$

Ketiga, berdasarkan dua langkah pertama tersebut, Abu Zayd mengusulkan sebuah pembaharuan hukum Islam. Dalam hukum Islam klasik, hukum poligami umumnya dibahas dalam bab "hal-hal yang di perbolehkan" (al-mubahat). Padahal, terma "pembolehan" (ibahah) menurut Abu Zayd tidaklah sesuai karena bahasan lain dalam bab tersebut mencakup pembolehan hal-hal yang tidak dibicarakan dalam teks, sementara pembolehan poligami dalam Al-Qur'an pada hakikatnya adalah pembatasan dari poligami sebelum datangnya Islam. Pembatasan, tegasnya, tidak berarti pembolehan. Idealnya, bagi Zayd, poligami dibahas dalam bab "pelarangan" (pengharaman) terhadap hal yang (sebelumnya) diperbolehkan (tahrim al-mubahat).

\section{Aplikasi Penafsiran Q.S. an-Nahl (16): 3-4}

Penciptaan langit dan bumi banyak disebutkan dalam al-Qur'an. Beberapa di antaranya menggambarkan proses tersebut secara global, beberapa lain secara rinci. Sebagian teks menyebutkan penciptaan langit saja, sebagian lain hanya menyebut penciptaan bumi. Kaitannya dengan ini, Abu Zayd mengawali paparannya dengan menyebut Q.S. An-Nahl (16): 3-4 berikut:

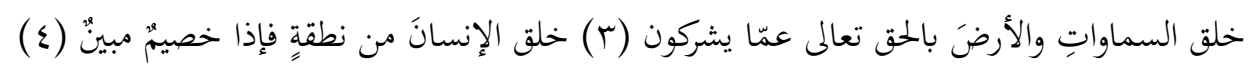

Artinya : Dia menciptakan langit dan bumi dengan hak, Maha Tinggi Allah daripada apa yang mereka persekutukan. Dia telah menciptakan manusia dari mani, (namun) tiba-tiba ia menjadi pembantah yang nyata.

Ayat di atas menyebutkan bahwa Allah menciptakan langit dan bumi dengan "al-Haq", sementara penciptaan manusia berasal dari air mani. Abu Zayd menggarisbawahi perbandingan antara dua hal ini dengan mengatakan bahwa penciptaan langit dan bumi dilakukan dengan al-Haq yang berarti pensucian sang pencipta terhadap dua ciptaan tersebut. Sementara itu, penciptaan manusia berasal dari air mani yang sangat hina sehingga menjadikan mereka sebagai pembantah yang mengingkari nikmat-nikmat-Nya. ${ }^{40}$

Bagi Abu Zayd, dua macam penciptaan tersebut menunjukkan hubungan paradoksal seperti halnya ayat-ayat yang menjelaskan bahwa penciptaan langit dan bumi lebih dahsyat dibanding penciptaan manusia. Salah satu di antara ayat tersebut adalah Q.S. al-Mu'minum (40): 57 berikut;

\footnotetext{
${ }^{39}$ Mochammad Nur Ichwan, Meretas Kesarjanaan Kritis al-Quran, 141.

${ }^{40}$ Q.S. al-Nahl \{16\}: 24-25.
} 


$$
\text { لخلْقُ السماواتِ والارض أكبرُ من خلق الناسٍ ولكنَّ أكثرَ اللناسِ لا يعلمون }
$$

Artinya: Sesungguhnya penciptaan langit dan bumi lebih besar daripada penciptaan manusia, akan tetapi kebanyakan manusia tidak mengetahui.

Abu Zayd menjelaskan bahwa konteks ayat di atas adalah pengingikaran terhadap Nabi Muhammad yang kemudian melahirkan ancaman bahwa kiamat begitu dekat dengan golongan penentang tersebut. Hubungan paradoksal yang demikian, lanjutnya, menunjukkan proses penciptaan yang berbeda. Proses penciptaan manusia terjadi melalui berbagai fase dimulai dari air mani hingga menjadi manusia seutuhnya, sementara penciptaan langit dan bumi dengan al-Haq tidaklah demikian.

Selain itu, Abu Zayd menunjukkan betapa dalam konteks ayat-ayat penciptaan langit dan bumi, ungkapan "bi al-Haq" muncul dalam formasi yang berbeda. Perselisihan pendapat mengenai makna "bi al-Haq" juga dipaparkannya dengan mengutip banyak informasi dari al-Tabari. Kata tersebut, menurut Abu Zayd yang disandarkan pada Tabari, berarti "benar" dengan lawan kata batil atau salah berdasarkan Q.S. Sad \{38\}: 27 berikut:

$$
\text { وما خلقنا السماء والأرضَ وما بينهما باطلا }
$$

Artinya: Dan Kami tidak menciptakan langit dan bumi dan apa yang ada antara keduanya dengan batil.

Ayat ini menurut Abu Zayd pada intinya menunjukkan bahwa langit dan bumi 'diciptakan' dengan bahan tertentu berdasarkan penggunaan huruf $b a^{\prime}$ dan alif lam yang menunjukkan bahan penciptaan, bukan sifatnya. Meski demikian, ia juga menyebutkan penafsiran lain yang mengatakan bahwa al-Haq berarti 'perkataan' Allah sebab ketika Allah berkehendak menciptakan sesuatu, ia akan 'berucap' jadilah/ kun" seperti yang dikemukakan dalam Q.S. Yasin (36) :82 berikut;

$$
\text { إنما أمرهُ إذا أراد شياًُ أن يقول له كن فيكن }
$$

Artinya: Sesungguhnya perintah-Nya apabila Dia menghendaki sesuatu hanyalah berkata kepadanya: "Jadilah!" maka terjadilah ia.

Dengan demikian, sedikitnya ada dua perbedaan pandangan perihal makna di balik al-Haq, yakni sebagai bahan penciptaan dan proses penciptaan. Abu Zayd cenderung pada penafsiran pertama.

\section{PENUTUP}

Ada beberapa teori kunci yang digunakan Abu Zayd dalam kerja hermeneutikanya, termasuk dalam menafsiri QS. an-Nisa (4): 3 dan al-Nahl (16): 3-4. Teori-teori tersebut di antaranya adalah perihal perbedaan tahapan tanzil dan $t a^{\prime} w i l$, nash dan mushaf, fungsi Al-Qur'an sebagai muntaj tsaqafi dan muntij tsaqafi, empat level pergeseran makna, hingga fase keterbentukan dan pembentukan. Berbekal berbagai teori tersebut, ia sampai pada kesimpulan bahwa Q.S. an-Nisa (4): 3 tidaklah memerintahkan 
poligami. Alih-alih demikian, ia menyiratkan bahwa kandungan ayat tersebut, dengan juga mempertimbangkan ayat-ayat lain dengan tema yang sama, sebenarnya menunjukkna pelarangan poligami secara samar. Sementara itu, al-Nahl (16): 3-4 yang memaparkan penciptaan langit dan bumi dengan al-haq menurutnya lebih menekankan pada bahan penciptaan dan bukan prosesnya.

\section{DAFTAR PUSTAKA}

Abdullah, Amin. "Pendekatan Hermeneutik dalam Studi Fatwa-fatwa Keagamaan: Proses Negosiasi Komunitas Pencari Makna Teks, Pengarang, dan Pembaca", dalam Pengantar buku Khaled M. Abou El-Fadl. Atas Nama Tuhan: Dari Fikih Otoriter ke Fikih Otoritatif. Jakarta: Serambi, 2004.

Chirzin, Muhammad. Fenomena Al-Qur'an "Diskusi Pemikiran Ulil Absar-Abdalla, Lutfhi Assyaukhani, dan Abd Moqsith Ghazali tentang Metodologi Studi Al-Qur'an. Yogyakarta: Pustaka Pelajar, 2018.

Hanafi, Hasan. 2009. Hermeneutika Al-Qur'an. Yogyakarta: Pesantren Nawesea Press, 2009. Hasan. Revolusi Seksual Perempuan. Bandung: Mizan, 1995.

Ichwan, Moch. Nur. Studi al-Qur'an Kontemporer: al-Qur'an sebagai Teks. Yogyakarta: PT. Tiara Wacana Yogya, 2002.

Ichwan. Moch. Nur, "Nasr Hamid Abu Zayd Dan Studi Al-Quran", Risalah, No. 11 Th. XXXV, Januari 1998.

Ichwan. Moch. Nur, Meretas Kesarjanaan Kritis al-Qur'an: Teori Hermeneutika Nasr Hamid Abu Zayd. Jakarta: Teraju, Cet.I, 2003.

Ichwan. Mochammad Nur, Meretas Kesarjanaan Kritis al-Quran: Teori Hermeneutika Nasr Abu Zayd. Jakarta: Teraju, 2003.

Kaelan, Metode Penelitian Agama Kualitatif Interdisipliner. Yogyakarta: Paradigma, 2010.

Kementerian Agama RI, Al-Qur'an dan Terjemahan. Bandung: Mikraj Khazanah Ilmu, 2016.

Kurdi (dkk). Hermeneutika al-Qur'an dan Hadis. Yogyakarta: Elsaq Press, 2010.

Mustaqim. Abdul. Metode Penelitian Al-Qur'an dan Tafsir. Yogyakarta: Idea Press, 2016.

Nasution. Khoiruddin, Riba dan Poligami: Studi atas Pemikiran Muhammad Abduh.Yogyakarta: Pustaka Pelajar dan ACAdeMIA, 1996.

Rahman, Fazlur. Membuka Pintu Ijtihad. Bandung: Pustaka, 1995.

Syamsuddin Arief, "Kisah Intelektual Nasr Hamid Abu Zain", 27 September 2020, http://muslimdelft.nl/titian_ilmu/ilmu_kalam_dan_aqidah/kisah_intelektu al_nasr_hamid_abu_Zain.php.

Usman. Ilmu Tafsir. Yogyakarta: Teras, 2009.

Zayd, Nashr Hamid Abu. Al-Imam al-Syafi wa Ta'sisu al-Idiyulujiyyah al-Wasatiyyah. Beirut: Al-Markaz al-Tsaqafi al-'Arabi, 2007.

Zayd, Nashr Hamid Abu. Wada'ir Al Khaif: Qira'ah Fi Khitab Al Mar'ah. Beirut: Dar Al Baidha, 2004. 
Zayd, Nasr Hamd Abu. Rethinking Qur'an: Towords a Humanistic Hermeneutics. Amsterdam: Humanistics University Press, 2004.

Zayd, Nasr Hamid Abu. Al-Quran Hermeneutik dan Kekuasaan, terj. Mochammad Nur Ichwan. Bandung: RQiS, 2003.

Zayd, Nasr Hamid Abu. Mafhum al-Nass. (Kairo: Al-Hai'ah al-Misriyyah al'Ammah li al-Kutub, 1990. 